\title{
A Geographic Information System (GIS)-Based Analysis of Social Capital Data: Landscape Factors That Correlate with Trust
}

\author{
Sohrab Rahimi ${ }^{1}$, Michael J. R. Martin ${ }^{2}$, Eric Obeysekere ${ }^{3}$, Daniel Hellmann ${ }^{3}$, Xi Liu ${ }^{4}$ \\ and Clio Andris ${ }^{4, *}$ \\ 1 Department of Architecture and Landscape Architecture, The Pennsylvania State University, \\ University Park, PA 16802, USA; sur216@psu.edu \\ 2 Department of Sociology and Criminology, The Pennsylvania State University, University Park, \\ PA 16802, USA; mjm842@psu.edu \\ 3 College of Information Sciences and Technology, The Pennsylvania State University, University Park, \\ PA 16802, USA; ero5004@psu.edu (E.O.); deh198@psu.edu (D.H.) \\ 4 Department of Geography, The Pennsylvania State University, University Park, PA 16802, USA; \\ xiliu@psu.edu \\ * Correspondence: clio@psu.edu; Tel.: +1-814-865-1175
}

Academic Editor: Marc A. Rosen

Received: 2 November 2016; Accepted: 24 February 2017; Published: 2 March 2017

\begin{abstract}
The field of community sociology has yielded rich insights on how neighborhoods and individuals foster social capital and reap the benefits of interpersonal relationships and institutions alike. Traditionally, institutions and cultural factors have been lauded as catalysts of community social life and cohesion. Yet, the built environment and configuration of the landscape, including infrastructure, amenities and population density, may also contribute to community social capital. In this article, we embedded zip code-level responses from Harvard University's Saguaro Seminar's 2006 Social Capital Community Benchmark Survey with a geographic information system. Specifically, we correlated responses on residents' general trust, trust of one's neighbors, and trust of members of other racial groups with local urban environmental factors and infrastructural indicators such as housing and street conditions, land use, city form, amenity access (e.g., libraries and schools), home vacancy rates, and home value. We conducted these tests at the national level and for Rochester, NY, due to its many survey responses. We found that housing vacancies drive down levels of social trust, as captured by homeownership rates and tenure, yielding higher levels of social trust, and that certain urban facilities correlate with high trust among neighbors. Results can inform urban planners on the amenities that support sustainable community ties.
\end{abstract}

Keywords: social capital; urban planning; trust; community sociology; geographic information systems; community goods; built environment

\section{Introduction}

The concept of social capital is increasingly gaining momentum among scholars, in part due to its broad range of applications that includes behavioral sciences, education, public health, political sciences and economics, as well as its traditional discipline of sociology [1-4]. Social capital can facilitate access to information, generate power among communities and construct settings for the advancement of social norms [4-11]. Other benefits of social capital are economic advancement and higher levels of economic equality [12-15], lower crime rates [14,16,17], inclination towards higher education [5,14], healthier communities $[13,14,18]$ more responsive governing systems, and increased chance of true 
democracy $[14,15,19,20]$. Each of these factors is tied to a sustainable society where the community can prosper and needs can be met without depleting human resources.

Multiple definitions have been proposed for social capital, and we use a loose definition that describes social capital as a construct manifested as helpful actions and resources within a group of people that precipitates common benefits [21-25]. Our definition of social capital vis-à-vis sustainability reflects the strength of connections: high trust levels within communities encourage investments in activities, infrastructure and public goods [26] that are likely to exist and be maintained in the future [27]. Social capital is cited as a keystone for sustainable development because it allows for easy access to external resources and opportunities that can benefit the community [28,29] (see [30] for a review). In other studies, trust has been seen as a mixed indicator of economic benefit, seemingly due to a mismatch between economic innovation and the security of existing relationships [31].

An understanding of how the correlation between the built environment and social capital (i.e., how the built environment can affect the growth of social capital within communities and, conversely, how social capital manifests itself in the context of built environment) can direct urban policies towards improving neighborhoods' quality and health [32]. In the United States particularly, new policies towards increasing neighborhoods' social capital are crucial, given a decline in social capital $[16,25]$ and trust [14] over the past decades. Researchers suggest a number of different factors, both spatial and non-spatial, have threatened social capital generation and sustenance, such as lack of residential ownership, fewer marriages and children, extensive use of television [25], extensive suburbanization [33], and over-crowdedness [34]. Also, higher vacancy rates and lower housing values are both linked to lower levels of social capital, while higher rates of homeownership are linked to more social capital as owners are more invested in their neighborhoods [35]. Characteristics of sustainable neighborhoods include investment in the local community and care of its residential properties. Developed open spaces, such as yards and parks, also may benefit social capital formation. Finally, a number of different amenities, such as libraries, museums and schools, may help individuals develop social contacts within their community and increase their overall levels of trust.

This study aims to identify urban-scale spatial factors associated with social capital. Theoretically, this research hinges on the fundamental assumption that accidental or intentional social interactions between neighbors can improve social capital in a neighborhood if frequent [36]. Moreover, frequent use of public spaces leads to a common sense of ownership over these spaces which further leads to development of social capital [37]. The qualitative and quantitative characteristics of the built environment, such as facilities, infrastructure and city form, can provide apt locales for co-presence and interaction of neighbors, promoting a healthy environment for relationships and cultivation of community assets. Increased personal investment in social and physical infrastructure leads to the upkeep and longevity of a healthy, sustainable community. Accordingly, we are interested in examining built environment factors that could exert an influence on neighborhood residents' inclination towards using common spaces.

\subsection{Background}

\subsubsection{The Spatial Side of Social Capital}

The relationship between the built environment and human social behavior includes a variety of perspectives and topics such as walkability, subjective well-being, access to public spaces, neighborhood satisfaction, surveillance and perception of safety, neighborhood liveliness, place attachment, etc. After an extensive literature review, we identify four categories of spatial variables pertaining to social behavior of neighborhood residents: street condition and spatial quality, housing conditions, land use and macroscale factors, and urban form and spatiality. In this section we aim to briefly discuss the previous studies and results with the purpose of identifying the influential physical factors pertaining to social capital. 


\subsubsection{Street Condition and Spatial Quality}

Streets are considered to be the hallmark of public spaces. Well-designed streets that attract populations and increase social interaction can improve social capital within neighborhoods. People depend on streets for a wide range of activities including travel, commuting, leisure and social activities [38-45].

Streets provide opportunities for stationary activities, that is, short-term activities where people linger for more than $15 \mathrm{~s}$ [35]. These activities encourage short-term interaction in a space that belongs to the entire neighborhood [46]. While these short-term interactions do not promise long-term and in-depth connections among neighbors, exposure to one another is a crucial first step to building local social capital that cannot be realized through online interactions [47].

Certain types of streets provide these interactions. At the macro-scale, high volumes of traffic and high-speed vehicles, along with noise and pollution, reduce the potentiality of positive social interaction [38]. For example, highways are known to be "lifeless" urban elements that cut through neighborhoods and deteriorate the connectedness of different districts within a neighborhood [48]. Instead, when possible, streets should be designed to facilitate a fine transition between local roads and major roads and minimize the traffic congestion [49].

On a more detailed level, spaces with convenient seating $[43,50-53]$ or that incorporate natural elements such as trees, grass, flowers, etc. attract more people to streets and increase chances for interactions [38,50,52-56]. Jacobs' The Death and Life of Great American Cities [45] explains the significance of sidewalks and their role in social life of residents, wherein the notion of "the eyes on street" implies that constant surveillance of streets can contribute to their safety and usability. When buildings have windows, a relatively small number of stories (fewer than six), or more than one entrance, pedestrians and others nearby tend to feel safer $[46,54,55]$.

\subsubsection{Housing Conditions and Residential Building Arrangement}

A neighborhood's housing conditions can reflect social, political and economic conditions [57-60]. Housing characteristics directly influence the level of satisfaction reported by residents; less-satisfied residents are more likely to relocate in pursuit of improved housing conditions [58]. In other words, attachment to neighborhood is considered to be a positive factor and residents with higher attachment to a place are more likely to use the common spaces in the neighborhood. Lack of residential ownership is also known to have negative effects on social capital [25,61].

The physical characteristics of residential buildings also influence the extent and quality of social interactions within a community [36]. Inadequate open spaces, a problem often associated with large high-rise residential buildings, affects the use of these spaces. Large buildings with tall, opaque walls are functionally disconnected from the surrounding streets, which gives residents less control over the surrounding spaces, thus alienating these spaces [54]. The arrangement of housing blocks can create semi-private spaces if buildings are strategically juxtaposed, increasing the community's sense of ownership over these spaces $[58,62]$. In terms of mixed land use, researchers argue that residential buildings collocated with other building types in close proximity could reduce infrastructure costs, lead to higher transportation efficiency and greater usable open spaces, and consequently create a greater level of social capital $[48,63,64]$.

\subsubsection{Land Use and Macroscale Factors}

Different aspects of land uses attract people to certain destinations. Most prominently, neighborhoods with a variety of shops and retail stores bring people to visit their streets [43,53,65-68]. This popularity extends to other third places (i.e., not work or home), such as restaurants, coffee shops, museums, libraries, churches, local organizations, etc., which attract different groups of people with similar interests and increase social encounters among individuals [37,42,69-73]. Researchers believe that open spaces with natural features also play an important role in fostering social interaction among 
individuals. For example, spaces with trees attract more heterogeneous age groups than spaces lacking trees [54]. Due to few open green spaces in cities and their simultaneous use by a number of different neighborhoods, open spaces play a significant role in bridging neighborhoods [74].

The juxtaposition of different land uses has long been a challenging component of design process for urban planners. However, there is a general consensus on some primary principles. For example, a mix of different types of spaces in a neighborhood precipitates more viable and attractive streets $[45,63,75-80]$. Yet, some believe that large complexes of shops and retail centers attract shoppers from adjacent neighborhoods and lead to physical decay in adjacent neighborhoods by eliminating business opportunities for other retailers in these neighborhoods [74]. The balance of land use and the distribution of commercial and gathering places is always in flux.

Macroscale spatial factors are those that extend beyond neighborhood boundaries. In some cases, these factors are not within the planners' control and involve either long-term policies or, in some cases, are entirely unmanageable. For example, some factors pertaining to environmental comfort, such as the region's climate and temperature [81,82], socioeconomic status and accessibility [83-85], municipal size [58], noise pollution, air pollution and crowdedness in a neighborhood $[38,54,86]$ and both psychological and physical safety [66] are important predictors of social behavior in a neighborhood.

\subsubsection{Urban Form and Spatiality}

A number of well recognized theories assert that the geometry and configuration of urban elements influences the likelihood of social encounters [87]. The proximity between certain spaces is a key factor in community growth $[88,89]$. For instance, residents within four houses from each other are more likely to become friends than those beyond four houses [90]. Moreover, the location of the key common urban spaces and the visual connection between different spaces within a neighborhood, e.g., visual links between residences, are important factors for social interaction [91,92]. In addition to configuration of spatial elements, the geometry of spaces is also a determinant factor. For example, large-scale privatization has led to large-grained urban textures-large buildings with solid windowless walls disconnected from the city $[93,94]$.

\section{Materials and Methods}

\subsection{Data}

\subsubsection{Social Capital Benchmark Community Survey Data}

The Social Capital Benchmark Community Survey is a national scale random telephone survey conducted in two waves during the spring and summer of 2006 [95] by the Saguaro Seminar at Harvard University. Data used in this study has been aggregated to the zip code level, as lower levels were not available. Data were obtained through the Roper Center (housed at the University of Connecticut at the time of data acquisition). Surveys were conducted in 23 targeted sampling areas with an additional national sample. Of 33,000 U.S. zip codes, these data cover roughly 3000 zip codes and 12,098 respondents. Most zip codes had few responses (Figure 1), while others had upwards of a few hundred. Although we are not permitted to disclose exact values, estimates at the county level can be found online [95].

The survey asks about 60 questions on civic engagement, including whether the respondent belongs to certain institutions such as a political club, whether he/she has friends with a vacation home or on welfare, attitudes on immigrants, inter-racial marriage, and whether he/she patronizes certain local facilities. Respondents are also asked for their zip code, gender, age range (28-34, $35-49,50-64,65+$ ), education level (high school, some college, college degree or more), and white or non-white race. 
We conducted two different analyses based on these data. First, we used the entire database for a national-level case study, and second, we performed a case study using one specific city, Rochester, NY. Rochester was chosen from the 23 targeted sampling areas because it had the most spatially-contiguous zip codes with over 10 respondents per zip code, while having a clear urban core, unlike rural sampling areas, which did not have an urban core associated with their contiguous zip codes. More specifically, land cover and total population count were used to classify individual zip codes in our study areas as either "urban" or "suburban" via the 2006 National Land Cover Dataset (NLCD) [96] at the 30-meter raster level was used to classify individual zip codes as "urban" or "suburban". Each zip code absorbed land cover types to produce a distribution of the fraction of each land cover type within the zip code. These results revealed Rochester's clear urban center based on land cover and population density variables. Comparing the pattern of zip codes identified in the hot spot analysis of the Saguaro counts, they appear to coincide with major road and passenger rail network arteries as well.

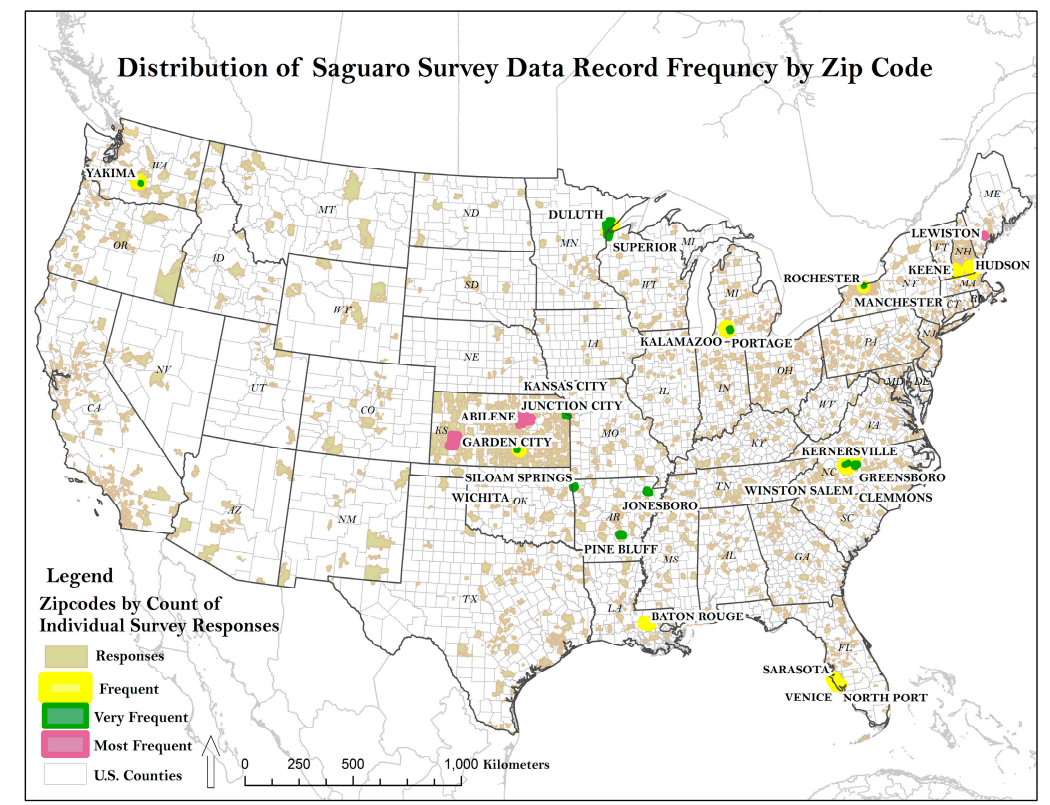

Figure 1. Response counts are highest for zip codes in Kansas and Lewiston (ME), with a number of states reporting a frequent number of survey responses (actual numbers not released). Survey requests have a similar spatial frequency. Outside of Kansas, Kalamazoo (MI), Baton Rouge (LA), Venice (CA), Winston-Salem and Greensboro (NC), and Rochester (NY) have the highest response counts from the U.S. national survey.

\subsubsection{Trust}

Three fields from the Saguaro Seminar survey were used as independent variables, including three variables related to trust: general trust, trust of one's neighbors, and trust of members of other racial groups.

The questions and possible answers (in parentheses) are listed here:

- Would you say that most people can be trusted or that you can't be too careful in dealing with people? (people can be trusted, you can't be too careful, depends (volunteered information))

- How much you can trust people in your neighborhood (a lot (coded as 1), some (2), a little (3), not at all (4), does not apply (volunteered information) (5), don't know (8), refused (9))

- How about white people? (same as neighborhood)

- What about African Americans or blacks? (same as neighborhood)

- What about Asian people? (same as neighborhood)

- How about Hispanics or Latinos? (same as neighborhood) 
The universal survey response for whether most people could be trusted showed that $44 \%$ said people could be trusted, $52 \%$ said you can't be too careful, and $4 \%$ volunteered that it depends [95]. Trust has been used as a primary indicator of social capital in many landmark past studies [97], so we find its use here appropriate as well. The Saguaro Survey asks questions about general trust, trust of neighbors and trust of different races. We calculated a combined variable that reflected a respondent's trust of races other than his or her own race. Our result is three variables: "Overall Trust", "Neighborly Trust" and "Trust, Other Races". In order to present our results intuitively, we inverted trust variables from their original meanings of $1=$ most trust and $4=$ least trust so larger values are equated with higher levels of trust on the same scale. This way, larger values are equated with higher levels of trust on the same scale. Respondents with missing variable responses were dropped from all models.

\subsubsection{Ancillary Data}

Demographic and landscape data are used to contextualize the zip codes in both the National and Rochester studies. The American Community Survey (ACS), a yearly nationally representative survey conducted by the U.S. Census, contains information on housing stock, structure and value, as well as other general demographic characteristics. The ACS provides data for each zip code in detail but is limited to the 5-year aggregation of data for reliable survey estimates for zip codes and smaller units. We selected data from the 2007-2011 ACS as it is the closest to when the survey was conducted. ACS variables were used as dependent variables that may correlate with trust. These variables represent the state of housing in a zip code and include the vacancy rate of each zip code, the percent of homes in each zip code that are owner occupied, and the median value of houses in each zip code (in thousands of USD).

Geolocated points of interest (POIs) including hospitals, schools, shopping centers, churches, recreation areas, museums, colleges and universities, government offices, and libraries in each zip code were extracted from online Esri datasets (via http://esri.com). These points were then spatially joined with zip code polygons, and a binary value for each category was assigned to the zip code where 1 represented the presence of that feature and 0 represented a lack of that feature. The binary values of the nine categories were then summed together to create a "built environment" variable which can be thought of as representing the variety of civic-inclined built features in a zip code. Also, the Annual Average Daily Traffic (AADT) [98] at the zip code level was used. The AADT is a measure used in transportation analysis and represents the total volume of the main roads divided by 365 . The AADT, collected through the portable traffic counter program, provided inventory counts taken on Federal and State highway systems at different locations.

\subsection{National Study}

We analyzed the overall national sample data using survey responses from the Saguaro Seminar as well as other secondary data from the American Community Survey and Esri. These variables were used in the regression analysis to account for the influence of the built environment on the independent variables. We calculated the relationship between landscape and social capital variables (Table 1) using a series of ordinary least squares (OLS) regression models. These models were adjusted to account for the survey design, including the sampling units and the unequal probability of selection for respondents.

To analyze nationwide data, we used OLS with "Overall Trust", "Neighborly Trust" and "Trust, Other Races" as our dependent variables. We regressed each response variable independently in a separate model. To account for the contextual effects and sampling procedures, we used cluster robust standard error [99]. Our response variables were reported on a Likert scale. However, we aggregated them at the zip code level, using the summary statistics of average. The aggregated scale is uni-dimensional, more reliable and has no fixed intervals between values. Accordingly, we treated response variables (i.e., the trust measures) as continuous values $[100,101]$. Each model was 
regressed on two predictor matrices: first, with only contextual variables (i.e., model 1) and second, including individual variables in addition to the context variables (i.e., model 2) (Table 2).

Table 1. Descriptive statistics for landscape and social capital variables by zip code.

\begin{tabular}{cccccc}
\hline & $\mathbf{N}$ & Mean & $\begin{array}{c}\text { Standard } \\
\text { Deviation }\end{array}$ & Minimum & Maximum \\
\hline Landscape variables & & & & & \\
$\quad$ Vacancy rate & 12,098 & 11.54 & 7.57 & 0.00 & 78.71 \\
Percent owner occupied & 12,098 & 65.83 & 14.76 & 0.00 & 100.00 \\
Median home value & 12,094 & $\$ 181,284$ & $\$ 121,980$ & $\$ 16,600$ & $\$ 1,000,001$ \\
Diversity of social amenities & 12,098 & 6.59 & 2 & 0 & 9 \\
\% Developed, open land & 12,098 & 12.83 & 10.18 & 0.00 & 64.61 \\
\hline Measures of social capital & & & & & \\
Overall trust & 12,000 & 1.03 & 1 & 0 & 2 \\
Trust in neighbors & 11,865 & 2.34 & 1 & 0 & 3 \\
Trust, other races & 10,703 & 2.11 & 1 & 0 & 3 \\
\hline
\end{tabular}

Table 2. Regression results for model 1(contextual only) and model 2 (contextual and individual) $(N=3000)$.

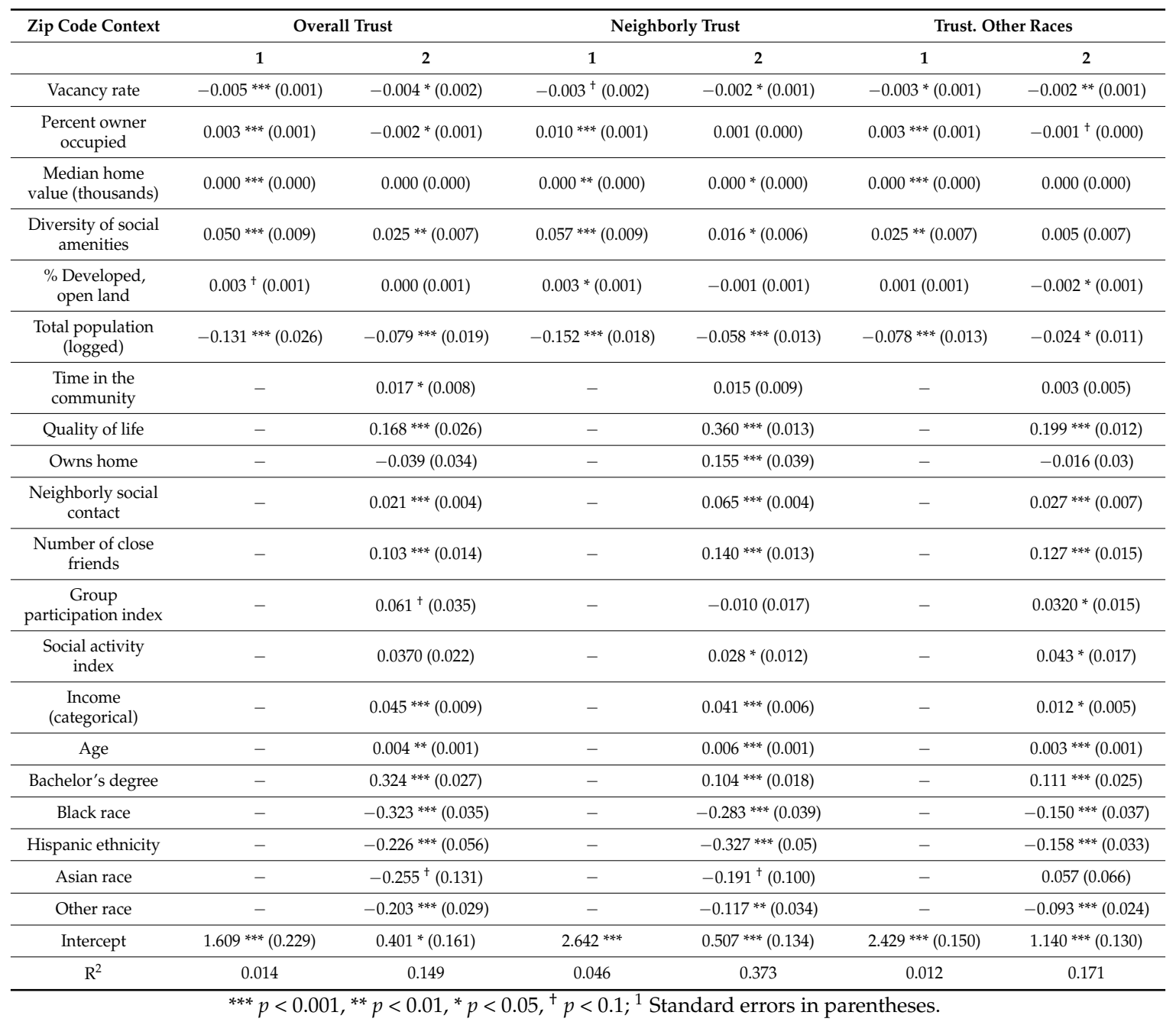

These individual variables include time in community, quality of life, home ownership, neighborly social contact, number of close friends, group participation index, social activity index, 
income, age, bachelor's degree, and black, Hispanic and Asian ethnicities. These variables are taken directly from the Saguaro Seminar individual responses. Importantly, these variables are non-geographic/non-contextual, in that they do not reflect the surrounding landscape, but the demographics and attitudes of the individual respondents.

\subsection{Rochester, NY Analysis}

An urban-scale analysis of neighborly trust and social capital was also conducted in order to address the main perspectives of the spatial side of social capital as described in the introduction. We focused on housing information and residents' accessibility to urban facilities. In the nationwide analysis, the number of schools, stores and hospitals within the built environment in each zip code were investigated, but the location of these facilities within each zip code was not investigated. We therefore analyzed individuals' access to these facilities by computing the service area of these features.

We focused on 15 zip codes of Rochester, NY, including zip codes in Genesee, Livingston, Monroe, Ontario, Orleans and Wayne Counties, totaling 700 surveyed individuals. This survey was oversampled to ensure that 100 Hispanics and 100 African Americans were represented in the sample [95,102]. Local facilities were classified into five categories, including parks (recreational areas, parks, amusement parks and lakes), schools (primary schools, high schools, colleges, universities, and recreational training clubs), stores (grocery stores and supermarkets), educational public places (libraries and museums) and worship places (churches and other religious places). For facility type, a service area was computed in ArcGIS with serving distances of $500 \mathrm{~m}, 1 \mathrm{~km}$ and $3 \mathrm{~km}$. For each zip code, the area accessible to an urban facility within travel distances of $500 \mathrm{~m}, 1 \mathrm{~km}$ or $3 \mathrm{~km}$ illustrates service areas (Figure 2).

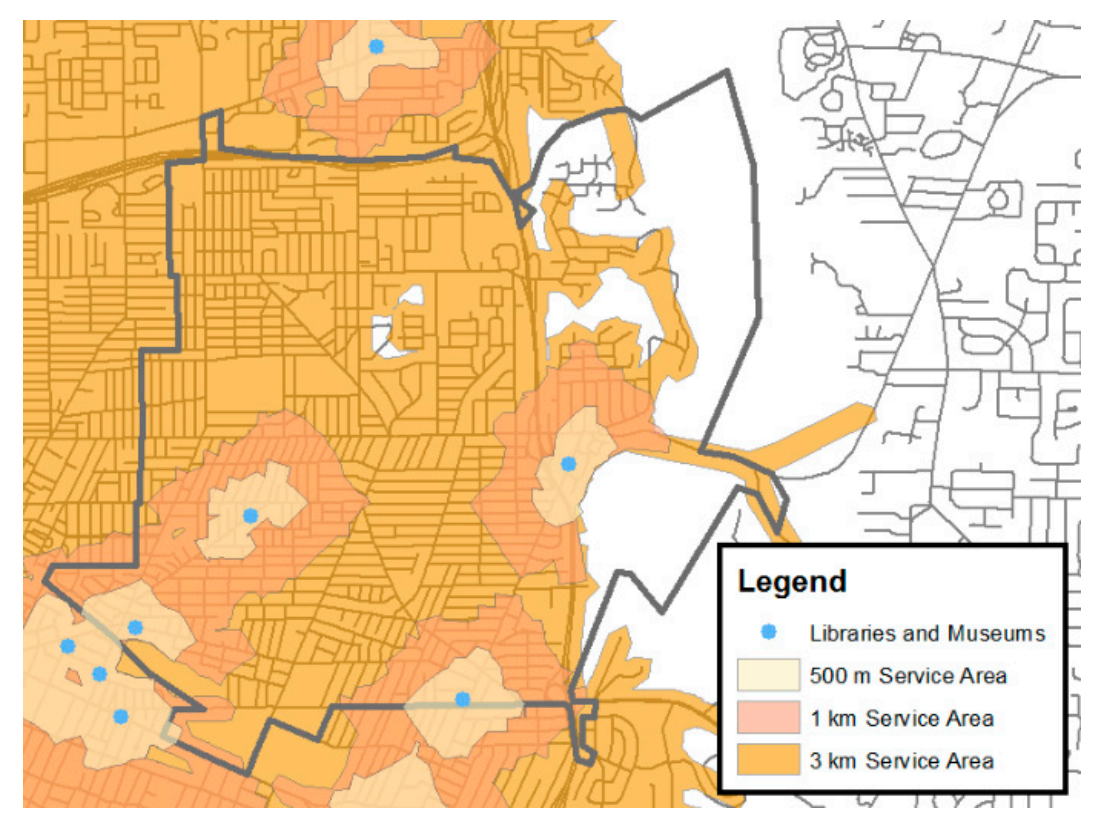

Figure 2. An illustration of service areas for amenities, such as libraries and museums, at travel distances of $500 \mathrm{~m}, 1 \mathrm{~km}$ and $3 \mathrm{~km}$.

The average AADT traffic count per zip code and U.S. Census [89] factors such as population density (i.e., estimated population divided by zip code area), vacancy rate, home ownership rate as well as the percentage of households with children, were used to describe socio-economics in zip codes. Since these factors are likely collinear, an ordinary least squares (OLS) model would cause multicollinearity and a considerable increase in variation inflation factor. To avoid these issues, we used a partial least squares (PLS) model which performs significantly better in such cases [103] as well as 
for small samples with relevantly high variance in both dependent and independent variables (the Rochester study has 15 zip codes with variance in variables).

We chose trust level between neighbors as the dependent variable in the final PLS model as this variable is representative of the social ties between neighbors, which is more likely to be affected by the built environment conditions than the other three trust factors.

\section{Results}

\subsection{National-Level Results: The Effect of Landscape on Trust}

Regressing trust variables on our chosen set of independent variables demonstrates a number of significant relationships in the direction we expect (Table 2). Model 1 includes only contextual variables and model 2 incorporates a number of individual characteristics found to be associated with social trust.

Geographic context has a significant association with overall trust. Coefficients for our independent variables in the model are small, but recall that trust ranges from 1 to 4 , with 4 indicating the highest amount of trust. Vacancy rate, homeownership rate, median housing value, and diversity in social amenity types all are significantly correlated with trust; the percent of land that is developed open space narrowly misses significance $(p=0.057)$. These associations occur in the expected direction. Of these contextual variables, diversity in amenity type is most strongly associated with social trust, as each additional amenity type is associated with a 0.05 increase in overall trust score.

In addition, overall population size plays a significant part in predicting social trust, with trust scores decreasing as the logged total population increases. Larger urban environments may lead to individuals becoming more disconnected with social groups, and therefore becoming less trusting. Among other important individual variables, the length of time a respondent lived in their community and the frequency with which they socialize with neighbors both play important roles in increasing general trust. These variables identify the degree to which an individual is embedded within their community, likely increasing the respondent's investment in and sense of ownership over their neighborhood. Despite the significance of zip code context in model 1, resulting $R^{2}$ values are quite low but increase roughly tenfold when we include individual determinants of trust. This means that contextual variables, although significant, do not explain variance in the data as well as individual factors.

Trust in neighbors shows similar, though stronger, results. The percent of land devoted to developed open spaces, while not significant for overall trust, is linked to slightly increased trust in one's neighbors. Amenity diversity is the most important positive coefficient in the first model. In the second model, while contextual variables become less important, diversity of amenities still shows significant positive association. Like with general trust, our findings reflect the literature: individuals trust their neighbors more in zip codes with smaller overall populations, more yards and parks, and a higher diversity of social amenities. Interestingly, the length of time one lived within their community does not have a significant effect on neighborly trust. This could be due to differences in how people conceptualize their community from their neighbors. Regarding the non-geographic variables, the frequency of neighborly socialization and diversity of social activity participation both have positive significant effects on neighborly trust, indicating that social embeddedness does in fact improve social capital with respect to trusting one's neighbors. Both contextual $\left(R^{2}=0.0456\right)$ and individual variables $\left(R^{2}=0.3729\right)$ explain substantially more of the variance in neighborly trust than their counterparts for overall trust or trust of other races. In addition, contextual variables explain a bigger share of the variance in our final models.

Out of the three trust variables, the relationship between spatial context and trust of members of other races is the weakest. As with general and neighborly trust, residents of more populated zip codes are less trusting, and higher vacancy rates also decrease trust of other races. Social amenities, homeownership rate and median housing value all increase trust in members of other races. However, 
most of these relationships become insignificant when we include individual variables. Only vacancy rate and total population remain significant with coefficients operating in the expected direction. The percent of land comprised of developed open space becomes significant and negatively associated with trust of other races.

\subsection{Rochester, New York Case Study}

Given the different measurement units for the variables, we standardized the data before fitting the PLS model. The results from the PLS model with 10 principal components explain $99.68 \%$ of the variance $\left(R^{2}=0.978\right)$. However, using 10 principal components causes overfitting. Since our model is designed for descriptive purposes and not prediction, cumulative explained variance of above $80 \%$ is acceptable [104]. Accordingly, we used five components in our final PLS regression model. This model explains $88 \%$ of the variance $\left(R^{2}=0.864\right)$. At last, we used the variable importance in projection (VIP) measure to investigate the extent of importance for each variable. We use a VIP of 1 as the cut-off point, that is, variables with VIPs larger than 1 are considered to be important factors [105]. Table 3 indicates the results of this regression.

The results indicate that home value is unequivocally the most important factor in determining the neighborly trust in Rochester, NY (VIP = 1.359). The higher the home value in a neighborhood in Rochester, the higher the average neighborly trust in that neighborhood. Neighborhoods with a high rate of families with children also show an important positive association with neighborly trust (VIP =1.151). Accessibility of the worship places and library/museums are both important variables, resulting in positive association with worship places (VIP $=1.138$ ) and negative with library/museums (VIP =1.118). Although the negative association of libraries and museums seems to be counterintuitive, it should be noted that there is a high correlation between the libraries/museums variable and traffic variable, which is also an important negative factor ( $\mathrm{VIP}=1.004)$. In other words, libraries and museums are located in crowded locations, which seems to have a negative association with trust. This correlation between different factors can be seen in the correlation circle (Figure 3).

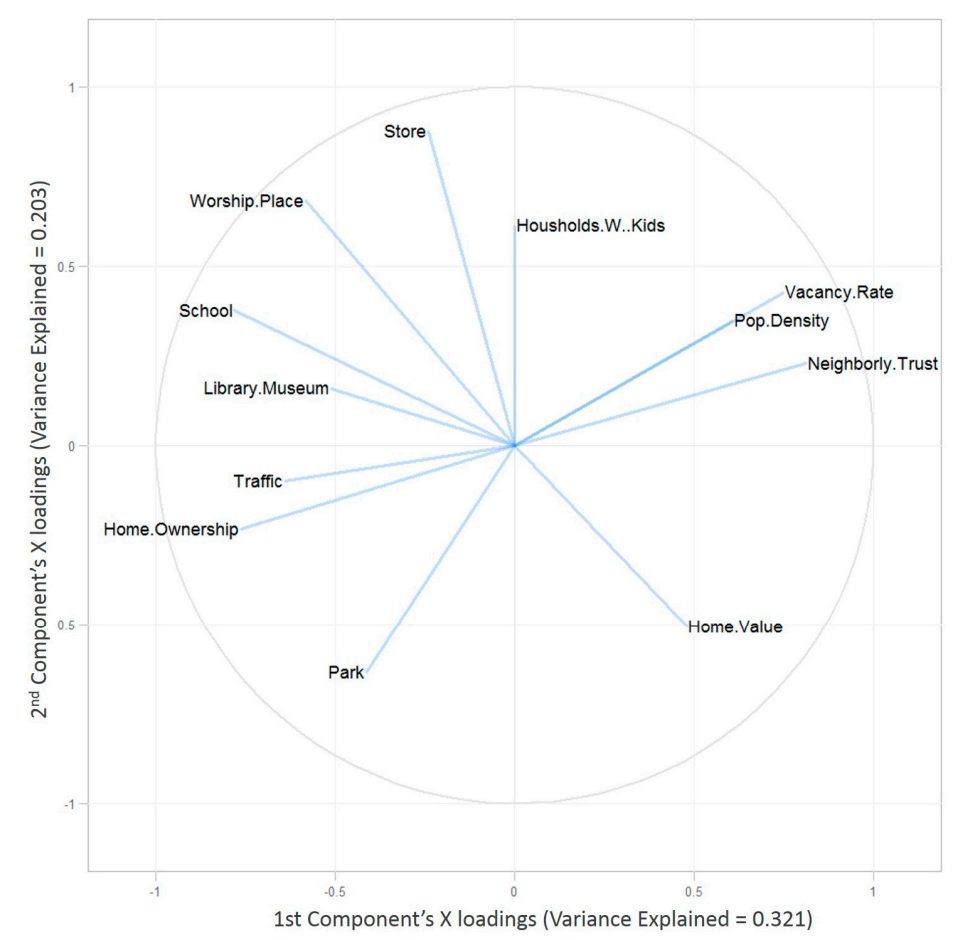

Figure 3. Correlation circle for different factors for the first two components. Most of the factors pertaining to the built environment (i.e., school, store, worship place, library/museum) are at odds with the neighborly trust in the first component but have a positive correlation with the second. 
Table 3. Partial least squares (PLS) regression coefficients, variable importance in projection (VIP) and first two principal components with five components for neighborly trust in Rochester, NY.

\begin{tabular}{ccccc}
\hline Variable & Coefficients & VIP & $\begin{array}{c}\text { First Component } \\
\text { (Var = 0.321) }\end{array}$ & $\begin{array}{c}\text { Second Component } \\
\text { (Var = 0.224) }\end{array}$ \\
\hline Population Density & 0.105 & 0.943 & 0.344 & -0.051 \\
Households with children & 0.416 & $1.151^{*}$ & 0.029 & 0.248 \\
Home Ownership & -0.203 & 0.818 & -0.446 & -0.259 \\
Vacancy Rate & 0.358 & 0.719 & 0.447 & 0.417 \\
Home Value & 0.82 & $1.359^{*}$ & 0.222 & -0.055 \\
Schools & 0.272 & 0.941 & -0.382 & 0.604 \\
Parks & 0.175 & 0.472 & -0.293 & -0.481 \\
Worship Places & 0.369 & $1.138^{*}$ & -0.258 & 0.614 \\
Libraries/Museums & -0.296 & $1.118^{*}$ & -0.239 & 0.392 \\
Stores & -0.108 & 0.723 & -0.044 & 0.695 \\
Traffic & -0.358 & $1.004^{*}$ & 0.336 & 0.311 \\
\hline
\end{tabular}

* Significant variables; ${ }^{1}$ variance explained by the component.

Accessibility to stores and parks does not show any significant association with trust. Regarding schools (VIP $=0.941$ ) and density (VIP $=0.943)$, the association is positive but the VIP is just smaller than 1. Vacancy rate and home ownership do not seem to be important factors. The interpretation of the predictor loadings shows that first and second principal components explain $32 \%$ and $20 \%$ of the variance, respectively. Home ownership and vacancy rate have the highest impacts in the first component. Home ownership is associated negatively with neighborly trust in both first and second components, although the second component's loading for ownership is not significant. Vacancy rate, on the other hand, shows a constantly positive and significant association with the first two components (Table 3). However, considering all five principal components, these two factors are not statistically significant because they have too many outliers in components three-five. A closer look at Rochester, NY reveals some general geographic patterns in the neighborly trust (Figure 4). Most zip codes close to the downtown area perform poorly in terms of trust.

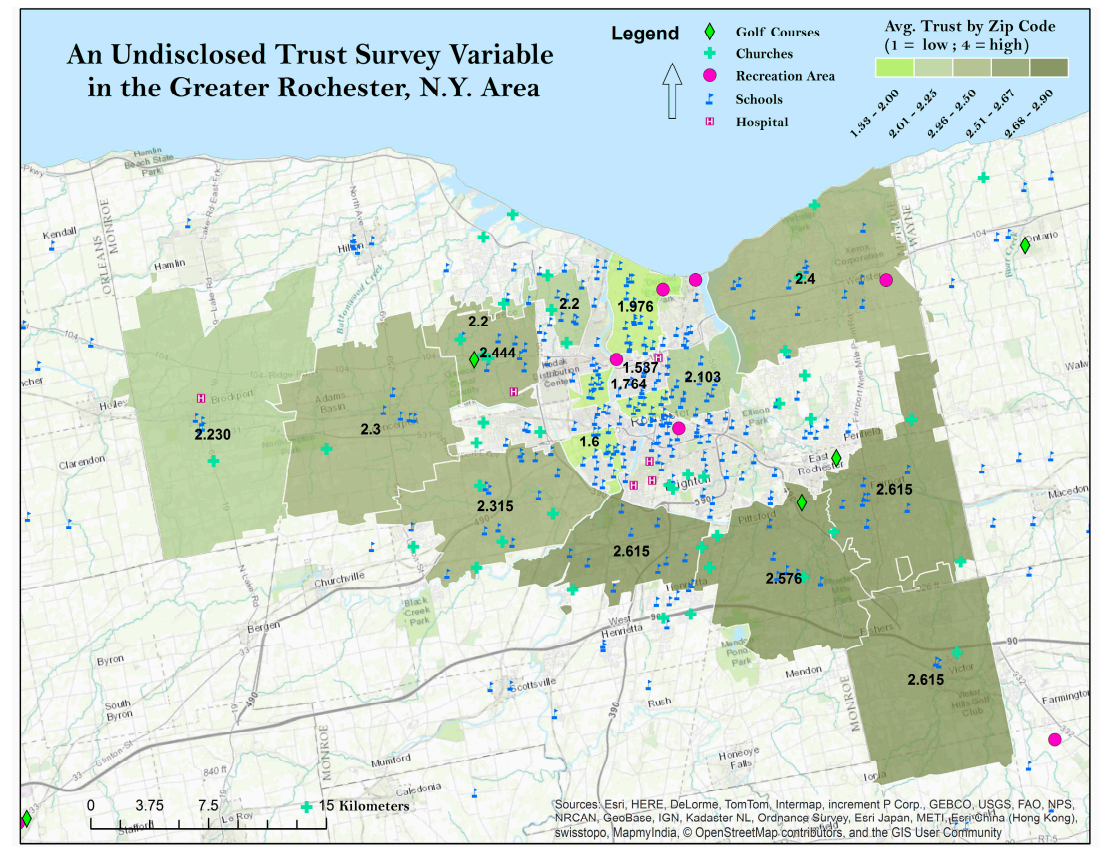

Figure 4. An example of trust variables mapped in geographic information system (GIS) and correlated with civic amenities in Rochester (NY) shows higher trust by zip code in the dense city center. There are a number of trust values in the survey, and the actual variable used is not disclosed. 


\section{Discussion and Conclusions}

Our results show some promise in analyzing the effect of the built environment and community context on social capital using a geographic information system (GIS). We modeled the civic landscape in tandem with salient social capital survey responses on trust rates. In our nationally representative study, we found that diversity of social amenities is frequently associated with higher levels of trust. Local access to some amenities was also associated with neighborly trust in our case study of Rochester, NY. Housing vacancies and larger populations both drove down levels of social trust, as these hinder the formation of social ties, especially with their neighbors. Social disorganization in larger urban environments as represented by vacant homes or lots, as well as crime, may disrupt the ability for people to increase their social capital. Investment in one's community, as captured by homeownership rates (at the zip code level) and length of time spent living in a community (at the individual level), was largely associated with higher levels of social trust [25,57].

In Rochester, NY, the proximity of some urban facilities correlated with higher trust level among neighbors. Our studies showed that neighborhoods with a higher trust level among neighbors are more likely to have certain urban facilities such as worship places and schools [73]. This analysis did not reveal any association between accessibility to stores and parks as suggested by some studies [51] but revealed negative impacts of crowdedness and traffic on the social climate [34]. Unlike in the national study, in Rochester most important factor correlating with neighborly trust was median home values, which highlights the importance of residential condition in neighborhoods as suggested by previous work $[54,56]$. Although this result is at odds with our national analysis, this could be the effect of the geographic context. Through this work, an offshoot of the scale problem known as the modifiable areal unit problem (MAUP), which challenges how areas or regions are defined as affecting data aggregation, is relevant to understanding a research question [106]. Accordingly, zip codes are a somewhat arbitrary level of measurement and may not represent one's neighborhood context well.

Also, in Rochester, NY, houses with high values are in the periphery, which might not be the case for other cities. Our research indicated that zip codes in suburban Rochester perform better in terms of neighborly trust. This finding is consistent with the impacts of some macroscale factors on the social climate of neighborhoods discussed in the previous research [34,51,62,79]. Unlike the national analysis, home ownership does not seem to affect neighborly trust in Rochester. Again, this issue might be due to the specific socio-spatial context of the study area.

Both studies indicated an association between the characteristics of the built environment and social capital. However, our research did not delineate whether certain spatial characteristics in the zip codes can actively improve social capital or these spatial characteristics are merely consequences of the social factors within a neighborhood. This issue opens up a horizon for future research to identify the spatial factors that could actively improve the social capital within communities as an important factor in sustainable development $[29,30]$.

Among the limitations of this study, access to useful and suitable ancillary data posed a problem for some thematic interests. For instance, zip code-level data related to pollution, safety, noise, and crime were remarkably difficult to locate or develop. This is likely a result of government and management disconnects between mail and census management as opposed to law enforcement and public safety. While we were able to adapt a few important and impactful datasets to support the national level analysis (land cover and institutions), leveraging the Saguaro data in future studies will require unusually creative and targeted data development.

Another key limitation of this study related to ancillary data access is the temporal disconnect between the 2006-era Saguaro data collection and temporal resolution of ancillary data used in this study. In most cases, we focused on sourcing data collected or developed between 2004 and 2006, but even this proved difficult, especially with transportation networks and flow data, American Community Survey (ACS) data, and real estate or institutional data. In some cases, we had no choice but to accept temporal displacement of as much as 8-9 years, creating internal validity issues within our results. Future studies could overcome this by investing resources in procuring or 
developing data with a 2006-era ground truth, but in the context of this study, those limitations are a substantial caveat.

Acknowledgments: We thank the Saguaro Seminar, led by Robert Putnam, at the Harvard Kennedy School of Government for providing the Social Capital Community Benchmark Survey data that was central to this study. Thank you especially to Thomas Sander for providing access to these data and for his guidance with the research. We thank the Roper Center (previously at the University of Connecticut) for logistics in data transfer. Thanks to Nathan Frey for helping us acquire data and for helpful discussions.

Author Contributions: Clio Andris, Daniel Hellmann, Xi Liu, Michael J. R. Martin, Eric Obeysekere and Sohrab Rahimi conceived and designed the experiments; Sohrab Rahimi and Michael J. R. Martin performed the experiments; Sohrab Rahimi and Michael J. R. Martin analyzed the data; Sohrab Rahimi and Clio Andris contributed reagents/materials/analysis tools; Sohrab Rahimi, Michael J. R. Martin and Clio Andris wrote the paper.

Conflicts of Interest: The authors declare no conflict of interest.

\section{References}

1. Jackman, R.W.; Miller, R. Social capital and politics. Annu. Rev. Political Sci. 1998, 1, 47-73. [CrossRef]

2. Portes, A.; Sensenbrenner, J. Embeddedness and immigration-Notes on the social determinants of economic-action. Am. J. Sociol. 1993, 98, 1320-1350. [CrossRef]

3. Woolcock, M. Social capital and economic development: Toward a theoretical synthesis and policy framework. Theory Soc. 1998, 27, 151-208. [CrossRef]

4. Adler, P.; Kwon, S. Social Capital: Prospects for a new concept. Acad. Manag. Rev. 2002, 27, 17-40.

5. Coleman, J.S. Social capital in the creation of human capital. Am. J. Sociol. 1988, 94, S95-S120. [CrossRef]

6. Geertz, C. The rotating credit association: A "middle rung" in development. Econ. Dev. Cult. Chang. 1962, 10, 241-263. [CrossRef]

7. Ouchi, W.G. Markets, bureaucracies, and clans. Adm. Sci. Q. 1980, 25, 129-141. [CrossRef]

8. Nelson, R.E. The strength of strong ties: Social networks and intergroup conflict in organizations. Acad. Manag. J. 1989, 32, 377-401. [CrossRef]

9. Uzzi, B. Social structure and competition in interfirm networks: The paradox of embeddedness. Adm. Sci. Q. 1997, 42, 35-67. [CrossRef]

10. Granovetter, M.S. The strength of weak ties. Am. J. Sociol. 1973, 78, 1360-1380. [CrossRef]

11. Krackhardt, D.; Hanson, J.R. Informal networks: The company. Harv. Bus. Rev. 1993, 71, 104-111. [PubMed]

12. Knack, S.; Keefer, P. Does social capital have an economic payoff? A cross-country investigation. Q. J. Econ. 1997, 112, 1251-1288. [CrossRef]

13. Kawachi, I.; Kennedy, B.P.; Lochner, K.; Prothrow-Stith, D. Social capital, income inequality, and mortality. Am. J. Public Health 1997, 87, 1491-1498. [CrossRef] [PubMed]

14. Clark, A.K. Rethinking the decline in social capital. Am. Politics Res. 2015, 43, 569-601. [CrossRef]

15. Fukuyama, F. Social capital and the global economy. Foreign Aff. 1995, 74, 89-103. [CrossRef]

16. Putnam, R. Social capital: Measurement and consequences. Can. J. Policy Res. 2001, 2, 41-51.

17. Wilson, H. Parental supervision re-examined. Br. J. Criminol. 1987, 27, 275-301. [CrossRef]

18. Wilkinson, R.G. Unhealthy Societies: The Afflictions of Inequality; Routledge: London, UK, 2002.

19. Paxton, P. Is social capital declining in the United States? A multiple indicator assessment. Am. J. Sociol. 1999, 105, 88-127. [CrossRef]

20. Uslaner, E.M. Producing and consuming trust. Political Sci. Q. 2000, 115, 569-590. [CrossRef]

21. Thomas, C.Y. Capital markets, financial markets and social capital: An essay on economic theory and economic ideas. Soc. Econ. Stud. 1996, 45, 1-23.

22. Inglehart, R. Modernization and Postmodernization: Cultural, Economic, and Political Change in 43 Societies; Cambridge University Press: Cambridge, UK, 1997.

23. Burt, R.S. Structural Holes: The Social Structure of Competition; Harvard University Press: Cambridge, MA, USA, 1992.

24. Coleman, J.S. Foundations of Social Theory; The Belknap Press of Harvard University: Cambridge, MA, USA, 1990.

25. Putnam, R.D. Bowling alone: America's declining social capital. J. Democr. 1995, 6, 65-78. [CrossRef] 
26. Pretty, J. Social capital and the collective management of resources. Science 2003, 302, 1912-1914. [CrossRef] [PubMed]

27. Abrams, R.F.; Malizia, E.; Wendel, A.; Sallis, J.; Millstein, R.A.; Carlson, J.A.; Cannuscio, C.; Glanz, K.; Samet, J.; Sleet, D.A.; et al. Making Healthy Places: Designing and Building for Health, Well-Being, and Sustainability; Island Press: Washington, DC, USA, 2012.

28. Selman, P. Social capital, sustainability and environmental planning. Plan. Theory Pract. 2001, 2, 13-30. [CrossRef]

29. Bebbington, A. Social capital and rural intensification: Local organizations and islands of sustainability in the rural Andes. Geogr. J. 1997, 163, 189-197. [CrossRef]

30. Dale, A.; Newman, L. Social capital: A necessary and sufficient condition for sustainable community development? Community Dev. J. 2010, 45, 5-21. [CrossRef]

31. Portes, A. Downsides of social capital. Proc. Natl. Acad. Sci. USA 2014, 111, 18407-18408. [CrossRef] [PubMed]

32. Irem, Ö.Z. Spatial representations of ideology and politics in urban scene: Keçiören example. J. Ank. Stud. 2014, 2, 131-158.

33. Oliver, J.E. Democracy in Suburbia; Princeton University Press: Princeton, NJ, USA, 2001.

34. Rodin, J. Density, perceived choice, and response to controllable and uncontrollable outcomes. J. Exp. Soc. Psychol. 1976, 12, 564-578. [CrossRef]

35. Mehta, V. Lively Streets: Determining Environmental Characteristics to Support Social Behavior. J. Plan. Educ. Res. 2007, 27, 165-187. [CrossRef]

36. Abu-Ghazzeh, T.M. Housing layout, social interaction, and the place of contact in Abu-Nuseir, Jordan. J. Environ. Psychol. 1999, 19, 41-73. [CrossRef]

37. Hester, R.T. Planning Neighborhood Space with People; Van Nostrand Reinhold: New York, NY, USA, 1984.

38. Appleyard, D. Livable streets: Protected neighborhoods? Ann. Am. Acad. Pol. Soc. Sci. 1980, 451, $106-117$. [CrossRef]

39. Francis, M. The making of democratic streets. In Public Streets For Public Use; Moudon, A.V., Ed.; Columbia University Press: New York, NY, USA, 1991.

40. Jacobs, A. Great Streets; MIT Press: Cambridge, MA, USA, 1993.

41. Southworth, M.; Ben-Joseph, E. Streets and the Shaping of Towns and Cities; Island Press: Washington, DC, USA, 2013.

42. Lofland, L.H. The Public Realm: Exploring the City's Quintessential Social Territory; Aldine de Gruyter: Naythonre, NY, USA, 1998.

43. Hass-Klau, C.; Crampton, G.; Dowland, C.; Nold, I. Streets as Living Space: Helping Public Places Play Their Proper Role; ETP/Landor: London, UK, 1999.

44. Heath, C.M.T.; Oc, T.; Tiesdell, M. Public Places-Urban Spaces, the Dimensions of Urban Design; Architectural Press: Burlington, MA, USA, 2003.

45. Jacobs, J. The Death and Life of Great American Cities; Vintage Books: New York, NY, USA, 1961.

46. Gehl, J. Life Between Buildings: Using Public Space; Van Nostrand Reinhold: New York, NY, USA, 1987.

47. Hampton, K.; Wellman, B. Neighboring in Netville: How the Internet supports community and social capital in a wired suburb. City Community 2003, 2, 277-311. [CrossRef]

48. Bothwell, S.E.; Gindroz, R.; Lang, R.E. Restoring community through traditional neighborhood design: A case study of Diggs Town public housing. Hous. Policy Debate 1998, 9, 89-114. [CrossRef]

49. Duany, A.; Plater-Zyberk, E. The Neighborhood, the District and the Corridor. New Urban. Towar. an Archit. Community; McGraw-Hill: New York, NY, USA, 1994; Volume XVII-XX.

50. Joardar, S.D.; Neill, J.W. The subtle differences in configuration of small public spaces. Landsc. Archit. 1978, $68,487-491$.

51. Linday, N. It all comes down to a comfortable place to sit and watch. Landsc. Archit. 1978, 68, $492-497$.

52. Share, L.A.P. Giannini plaza and Transamerica park: Effects of their physical characteristics on users' perception and experiences. In New Directions in Environmental Design Research; Rogers, W., Ittelson, W., Eds.; EDRA: Washington, DC, USA, 1978; pp. 127-139.

53. Whyte, W.H. The Social Life of Small Urban Spaces; The Conservation Foundation: Washington, DC, USA, 1980.

54. Coley, R.L.; Sullivan, W.C.; Kuo, F.E. Where does community grow? The social context created by nature in urban public housing. Environ. Behav. 1997, 29, 468-494. [CrossRef] 
55. Sullivan, W.C.; Kuo, F.E.; Depooter, S.F. The fruit of urban nature vital neighborhood spaces. Environ. Behav. 2004, 36, 678-700. [CrossRef]

56. Newman, O. Defensible space: Crime prevention through urban design. Ekistics 1973, 7, 325-332.

57. Form, W.H. The place of social structure in the determination of land use: Some implications for a theory of urban ecology. Soc. Forces 1954, 32, 317-323. [CrossRef]

58. Fried, M. Residential attachment: Sources of residential and community satisfaction. J. Soc. Issues 1982, 38, 107-119. [CrossRef]

59. Buttimer, A. Social space and the planning of residential areas. Environ. Behav. 1980, 4, 279-318.

60. Rahimi, S.; Liu, X.; Andris, C. Hidden style in the city: An analysis of geolocated airbnb rental images in ten major cities. In Processdings of the 2nd ACM SIGSPATIAL Work. Smart Cities and Urban Analytics, UrbanGIS'16, New York, NY, USA, 31 October 2016; pp. 1-7.

61. De Souza Briggs, X. Brown kids in white suburbs: Housing mobility and the many faces of social capital. Hous. Policy Debate 1998, 9, 177-221. [CrossRef]

62. Yancy, W.L. Architecture, interaction and social control. Environ. Behav. 1971, 3, 3-21. [CrossRef]

63. Calthorpe, P. The Next American Metropolis: Ecology, Community, and the American Dream; Architectural Press: Princeton, NJ, USA, 1993.

64. Ewing, R.H. Characteristics, causes, and effects of sprawl: A literature review. In Urban Ecology; Marzluff, J.M., Ed.; Springer: Berlin/Heidelberg, Germany, 2008; pp. 519-535.

65. Montgomery, J. Making a city: Urbanity, vitality and urban design. J. Urban Des. 1998, 3, 93-116. [CrossRef]

66. Altschuler, A.; Somkin, C.P.; Adler, N.E. Local services and amenities, neighborhood social capital, and health. Soc. Sci. Med. 2004, 59, 1219-1229. [CrossRef] [PubMed]

67. Alexander, C. A Pattern Language: Towns, Buildings, Construction; Oxford University Press: Oxford, UK, 1977.

68. Banerjee, T.; Loukaitou-Sideris, A. Private Production of Downtown Public Open Space: Experiences of Los Angeles and San Francisco; School of Urban and Regional Planning, University of Southern California: Los Angeles, CA, USA, 1992.

69. Hester, R. Sacred structures and everyday life: A return to Manteo, North Carolina. In Dwelling, Seeing, and Designing; Seamon, D., Ed.; SUNY Press: Albany, NY, USA, 1993; pp. 271-297.

70. Warren, D.I. Black Neighborhoods: An Assessment of Community Power; University of Michigan Press: Ann Arbor, MI, USA, 1975.

71. Bourke, C. Public libraries: Building social capital through networking. Aust. Public Libr. Inf. Serv. 2005, 18, $71-75$.

72. Leyden, K.M. Social capital and the built environment: The importance of walkable neighborhoods. Am. J. Public Health 2003, 93, 1546-1551. [CrossRef] [PubMed]

73. Swart, I. Churches as a stock of social capital for promoting social development in Western Cape communities. J. Relig. Afr. 2006, 36, 346-378. [CrossRef]

74. Foster, S. The city as an ecological space: Social capital and urban land use. Notre Dame Law Rev. 2006, 82, 527-582.

75. Kunstler, J.H. Geography of Nowhere: The Rise And Decline of America's Man-Made Landscape; Simon and Schuster: New York, NY, USA, 1994.

76. Ewing, R. Best Development Practices-Doing the Right Thing and Making Money at the Same Time; American Planning Association: Chicago, IL, USA, 1996.

77. Coupland, A. Reclaiming the City: Mixed Use Development; Taylor \& Francis: London, UK, 1997.

78. Duany, A.; Plater-Zyberk, E.; Speck, J. Suburban Nation: The Rise of Sprawl and the Decline of the American Dream; North Point Press: New York, NY, USA, 2000.

79. Bentley, I. Responsive Environments: A Manual for Designers; Architectural Press: Oxford, UK, 1985.

80. Krier, L. Architecture and Urban Design 1967-1992; St. Martin's Press: New York, NY, USA, 1992.

81. Bosselmann, P.; Flores, J.; Gray, W.; Priestley, T.; Anderson, R.; Arens, E.; Dowty, P.; So, S.; Kim, J.-J. Sun, Wind, and Comfort: A Study of Open Spaces and Sidewalks in Four Downtown Areas; Intersitute of Urban and Regional Development: Berkeley, CA, USA, 1984.

82. Arens, E.; Bosselmann, P. Wind, sun and temperature-Predicting the thermal comforf of people in outdoor spaces. Build. Environ. 1989, 24, 315-320. [CrossRef]

83. Cervero, R. Mixed land-uses and commuting: Evidence from the American Housing Survey. Transp. Res. Part A Policy Pract. 1996, 30, 361-377. [CrossRef] 
84. Cervero, R.; Kockelman, K. Travel demand and the 3Ds: Density, diversity, and design. Transp. Res. Part D Transp. Environ. 1997, 2, 199-219. [CrossRef]

85. Kitamura, R.; Mokhtarian, P.L.; Laidet, L. A micro-analysis of land use and travel in five neighborhoods in the San Francisco Bay Area. Transportation 1997, 24, 125-158. [CrossRef]

86. Baba, Y.; Austin, D.M. Neighborhood environmental satisfaction, victimization, and social participation as determinants of perceived neighborhood safety. Environ. Behav. 1989, 21, 763-780. [CrossRef]

87. Hillier, B.; Hanson, J. The Social Logic of Space; Cambridge University Press: Cambridge, UK, 1989.

88. Kearns, A.; Parkinson, M. The significance of neighbourhood. Urban Stud. 2001, 38, 2103-2110. [CrossRef]

89. Kleit, R.G. HOPE VI new communities: Neighborhood relationships in mixed-income housing. Environ. Plan. A 2005, 37, 1413-1441. [CrossRef]

90. Festinger, L. Informal social communication. Psychol. Rev. 1950, 57, 271. [CrossRef] [PubMed]

91. Raman, S. Designing a liveable compact city physical forms of city and social life in urban neighbourhoods. Built Environ. 2010, 36, 63-80. [CrossRef]

92. Rahimi, S. Social Interaction in Student Residence Halls: An Architectural Perspective. Ph.D. Dissertation, The Pennsylvania State University, State College, PA, USA, 2015.

93. Jacobs, A.; Appleyard, D. Toward an urban design manifesto. J. Am. Plan. Assoc. 1987, 53, 112-120. [CrossRef]

94. Davis, M. City of Quartz; Verso: London, UK, 2010.

95. Harvard Kennedy School Saguaro Seminar 2006 Social Capital Community Survey. Available online: https://www.hks.harvard.edu/programs/saguaro/measurement/sk-2006-community-benchmark-survey (accessed on 1 October 2016).

96. Fry, J.; Xian, G.; Jin, S.; Dewitz, J.; Homer, C.G.; Yang, L.; Barnes, C.; Herold, N.D.; Wickham, J.D. Completion of the 2006 National Land Cover Database for the conterminous United States. Photogramm. Eng. Remote Sens. 2011, 77, 858-864.

97. Narayan, D.; Cassidy, M.F. A dimensional approach to measuring social capital: Development and validation of a social capital inventory. Curr. Sociol. 2001, 49, 59-102. [CrossRef]

98. Data.Gov. State of New York-Annual Average Daily Traffic (AADT): Beginning 1977. Available online: https: / / catalog.data.gov / dataset?res_format=CSV\&tags=aadt\&organization=state-of-new-york (accessed on 15 November 2015).

99. Cameron, A.C.; Miller, D.L. A practitioner's guide to cluster-robust inference. J. Hum. Resour. 2015, 50, 317-372. [CrossRef]

100. Glass, G.V.; Peckham, P.D.; Sanders, J.R. Consequences of failure to meet assumptions underlying the fixed effects analyses of variance and covariance. Rev. Educ. Res. 1972, 42, 237-288. [CrossRef]

101. Lubke, G.H.; Muthén, B.O. Applying multigroup confirmatory factor models for continuous outcomes to Likert scale data complicates meaningful group comparisons. Struct. Equ. Model. A Multidiscip. J. 2004, 11, 514-534. [CrossRef]

102. Easterling, D. Promoting community leadership among community foundations: The role of the Social Capital Benchmark Survey. Found. Rev. 2011, 3, 81-96. [CrossRef]

103. Farahani, H.A.; Rahiminezhad, A.; Same, L. A Comparison of partial least squares (PLS) and ordinary least squares (OLS) regressions in predicting of couples mental health based on their communicational patterns. Procedia-Soc. Behav. Sci. 2010, 5, 1459-1463. [CrossRef]

104. Minitab 17 Support. Ways to Determine the Number of Prinicpal Components. Available online: http:/ / support.minitab.com/en-us/minitab/17/topic-library/modeling-statistics/multivariate/principalcomponents-and-factor-analysis/number-of-principal-components (accessed on 2 February 2016).

105. Mehmood, T.; Liland, K.H.; Snipen, L.; Sæbø, S. A review of variable selection methods in partial least squares regression. Chemom. Intell. Lab. Syst. 2012, 118, 62-69. [CrossRef]

106. Kwan, M.-P.; Weber, J. Scale and accessibility: Implications for the analysis of land use-Travel interaction. Appl. Geogr. 2008, 28, 110-123. [CrossRef]

(C) 2017 by the authors. Licensee MDPI, Basel, Switzerland. This article is an open access article distributed under the terms and conditions of the Creative Commons Attribution (CC BY) license (http://creativecommons.org/licenses/by/4.0/). 